Int. J. Electrochem. Sci., 15 (2020) 10936 - 10954

International Journal of

ELECTROCHEMICAL

SCIENCE

www.electrochemsci.org

Review

\title{
Design Strategies for Enhancing the Electrochemical Performance of Li-Rich Cathode Materials for Lithium-Ion Batteries
}

Chen $\mathrm{Hu}^{1, \dagger}$, Yi Jin ${ }^{1, \dagger}$, Tianfeng Geng ${ }^{2, \dagger}$, Dandan Sun ${ }^{2}$, Chunyu Du ${ }^{2, ~ *}, J_{i y u a n}$ Jian $^{2}$, Geping Yin $^{2}$

${ }^{1}$ State Key Laboratory of Operation and Control of Renewable Energy \& Storage Systems, China Electric Power Research Institute, Beijing 100192, China

${ }^{2}$ MIIT Key Laboratory of Critical Materials Technology for New Energy Conversion and Storage, School of Chemistry and Chemical Engineering, Harbin Institute of Technology, Harbin 150001, China

$\dagger$ These authors contributed equally.

*E-mail: cydu@hit.edu.cn

doi: $10.20964 / 2020.11 .63$

Received: 8 April 2020 / Accepted: 27 August 2020 / Published: 30 September 2020

Lithium-ion batteries (LIBs) are one of the most promising energy storage technologies for many applications, such as environmentally friendly transportation. The cathode is the most important material in LIBs and determines mainly their energy density, life and cost. Li-rich layered oxides $\mathrm{xLi}_{2} \mathrm{MnO}_{3} \cdot(1-\mathrm{x}) \mathrm{LiMO}_{2}(\mathrm{M}=\mathrm{Mn}, \mathrm{Ni}, \mathrm{Co})$ have been recognized as the most attractive candidates for next-generation cathode materials due to their extremely high reversible capacity. However, severe technical issues (mainly, the low initial Coulomb efficiency, poor rate capability, and voltage decay during cycling) need to be addressed. In this review, we summarize recent research progress on Li-rich layered oxide cathode materials. We focus on new strategies for tackling the technical challenges of Li-rich layered oxide cathode materials, which include exposing preferential crystal planes, inducing oxygen/lithium defects, forming spinel-layered or olivine-layered heterogeneous structures and tuning the lattice structure. Future research directions for Li-rich cathode materials are finally proposed for commercial applications.

Keywords: Lithium-ion batteries, Cathode materials, Li-rich layered oxides, Heterogeneous structures, Cycling stability

\section{FULL TEXT}


(C) 2020 The Authors. Published by ESG (www.electrochemsci.org). This article is an open access article distributed under the terms and conditions of the Creative Commons Attribution license (http://creativecommons.org/licenses/by/4.0/). 